\title{
Analysis of Tire-Pavement Noise Spectrum of Noise Reduction Dense Asphalt-rubber Pavement
}

\author{
GUO Zhao-yang ${ }^{1,2, a}$, FENG De-cheng ${ }^{1, b}$, SHEN Guo-hui ${ }^{2, c}$ \\ ${ }^{1}$ School of Transportation Science and Engineering, Harbin Institute of Technology, Harbin 150090, \\ China \\ ${ }^{2}$ Research Institute of Highway Ministry of Transportation ,Beijing ,100088, China \\ achaoyang226@163.com, bfdcgxy@vip.sina.com, gh.shen@rioh.cn
}

Keywords: asphalt-rubber pavement; noise spectrum ; Close-Proximity (CPX) method ; tire-pavement noise ;

\begin{abstract}
The types of noise reduction asphalt pavement were summarized into the follows: single layer porous or two-layer porous asphalt pavement, elastic asphalt pavement, optimized surface texture pavement, and universally composable one based on these three types. Beijing of China was very drought and short of rainfall, there were large volume of traffic, heavy wheel load and many dirt things on the pavement surface taken by the tires too. So the dense asphalt-rubber pavement was the most common one for noise reduction, which was paved by gap-graded, macro-texture, dense asphalt concrete, belonging to the types of elastic and optimized surface texture noise reduction pavement. And it could reduce tire-pavement noise obviously and had excellent durability; all proved that it had gone through traffic and climate environment of Beijing well. It had measured tire-pavement noise of asphalt-rubber pavement and stone mustic asphalt pavement in Beijing from 2009 to 2012. This measurement was according to Measurement of close-proximity method which prepared by international organization for standardization in the year 2000. And the test vehicle was a trailer for measuring tire-pavement noise which met requirements of ISO/CD 11819-2:2000. The factors affecting tire-pavement noise spectrum were analyzed, such as temperature, speed, age of pavement and so on. It reveals that the tire-pavement noise sound level could get higher especially higher during the frequency $500 \mathrm{~Hz} 2500 \mathrm{~Hz}$ in the noise spectrum, while the testing speed increase, or the temperature decrease, or the age of pavement grow. While the frequency lay on the range of higher than $800 \mathrm{~Hz}$, the asphalt-rubber pavement's noise sound level were lower than the stone mustic asphalt pavement's one in all situations, and when the temperature decreased from $30^{\circ} \mathrm{C}$ to $0^{\circ} \mathrm{C}$, the low limit frequency decreased from $800 \mathrm{~Hz}$ to $63 \mathrm{~Hz}$. It had tested dynamic modulus and phase angle of the two kinds of pavement materials under different temperature and load frequency with the help of Simple Performance Tester in order to show the reason, The result shows that, asphalt-rubber concrete has smaller Phase angle at wide temperature as well as frequency changes, it could be one of the main reasons to explain this phenomenon. It could provide reference for designing, constructing, maintaining and evaluating the noise reduction asphalt pavement.
\end{abstract}

\section{Introduction}

Asphalt-rubber pavement had been used in Beijing for more than 10 years primarily because it could reduce the premature failures of asphalt pavement. And it could recycle and utilize lots of waste tires by machining them into powder and adding them into asphalt mixture, and contributing to environmental protection of Beijing. Moreover, it could reduce tire-pavement noise, and had been extensively used in Beijing to obtain these benefits. The dense asphalt-rubber pavement was the most widely used in urban road in the last decade, whose nominal maximum aggregate sizes were mainly $13 \mathrm{~mm}$ or $10 \mathrm{~mm} .{ }^{[1]}$ However, its noise reducing properties is not well known compared with other asphalt pavement. There should be proof of adequate performance for dense asphalt-rubber pavement to be accepted as a noise mitigation tool. 
Beijing Municipal Science \& Technology Commission had spent RMB 2 million to study the technology of designing, constructing, maintaining and evaluating the noise reduction asphalt pavement in 2007. It would help to build greener and quieter Beijing, achieving the aim of improving the quality of life of citizens ${ }^{[2]}$.

Research Institute of Highway Ministry of Transportation was asked to conduct the research. it had studied acoustic properties and mechanical properties of several types of asphalt mixture used in Beijing with the help of advanced test equipment, such as Simple Performance Tester, Universal Testing Machine, Asphalt Pavement Analyzer, Reverberation Room. And developed a new noise reduction asphalt pavement, which was paved by gap graded, macrotexture, dense asphalt-rubber mixture, It had invented a trailer with weight to measure tire-pavement noise in accordance with close-proximity method-proposed in ISO/CD 11819-2:2000. ${ }^{[2]}$

The preliminary findings presented here are analysis of tire-pavement noise spectrum of noise reduction dense asphalt-rubber pavement. After measuring tire-pavement noise five times in Chang'an Avenue from 2009 to 2012, it had gotten the difference between asphalt-rubber pavement's noise spectrum and stone mustic asphalt pavement's one. The factors affecting tire-pavement noise spectrum were analyzed, such as temperature, speed, age of pavement and so on. In order to show the reasons for the differences, this paper presents the correlations of noise spectrum with viscoelasticity of two kinds of pavement materials, by testing their dynamic modulus and phase angle under different temperature and load frequency.

\section{Testing program}

Close-Proximity Trailer (CPXT) method for tire-pavement noise ${ }^{[3]}$

Close-Proximity Trailer (CPXT) method is used for evaluating the noise characteristic of pavement in driving condition. CPXT method is recommended according to the close-proximity method - from Part 2 of Acoustics - Measurement of the influence of road surfaces on traffic noise in Technical Committee ISO/TC 43, Acoustics, Subcommittee SC 1, Noise. The average A-weighted sound pressure levels emitted by one specified reference tire are measured over a specified road distance, together with the vehicle testing speed, by at least two microphones, located close to the tires according to the method. The two mandatory microphones should be operated simultaneously and should have fixed positions relative to the test tire, such that the distance horizontally from the plane of the near test tires sidewall is $0.20 \mathrm{~m}( \pm 0.02 \mathrm{~m})$. The two mandatory microphones should be mounted at a height above pavement level of $0.10 \mathrm{~m}( \pm 0.02 \mathrm{~m})$. The front microphone should be mounted at an angle of $45^{\circ} \pm 5^{\circ}$ to the rolling direction as and the rear microphone shall be mounted at an angle of $135^{\circ} \pm 5^{\circ}$ to the rolling direction.

According to ISO 11819-2Acoustic, performance requirements of trailers used in measuring tire-pavement noise should be met mainly on two aspects: background noise and sound reflections against the enclosure. ${ }^{[4],[5]}$

The background noise of the entire test system must not influence the third octave-band levels more than $1 \mathrm{~dB}$ in the $500 \mathrm{~Hz}-4000 \mathrm{~Hz}$ frequency range and more than $2 \mathrm{~dB}$ in the $315 \mathrm{~Hz}-400 \mathrm{~Hz}$ range.

The influence of sound reflections against the enclosure should be smaller. Any influence greater than $1.0 \mathrm{~dB}$ in the third-octave-band spectra should be reported and all later measurements should be corrected accordingly to represent the case without enclosure (free-field).

Acoustics performance evaluation result of this trailer is shown in Table 1. The testing speed is $50 \mathrm{~km} / \mathrm{h}$. Tire-pavement noise was evaluated by sound pressure level under the third octave-band frequency. The result is shown by average A-weight sound level. 
Table 1: Performance test results of the trailer for tire-pavement noise measurements

\begin{tabular}{|c|c|c|}
\hline Items & Results & Requirements \\
\hline Pavement Temperature $\left({ }^{\circ} \mathrm{C}\right)$ & 22.0 & $23 \pm 3$ \\
\hline Sound reflections against the enclosure dB (A) & 0.6 & $<1$ \\
\hline Ambient noise dB (A) & 50.0 & $<$ Background noise sound pressure level \\
\hline Background noise dB (A) & 79.4 & Field test \\
\hline Tire -pavement sound pressure level dB (A) & 91.2 & $\begin{array}{c}\text { Differential value exceeds 10dB, when compared with } \\
\text { background noise }\end{array}$ \\
\hline
\end{tabular}

Test method for dynamic modulus and phase angle ${ }^{[6]}$

Simple Performance Tester was used, the test method for dynamic modulus and phase angle followed National Cooperative Highway Research Program (NCHRP) Project 9-19 simple performance tests.

Size of test specimen: cylindrical specimens of $15 \mathrm{~cm}$ in diameter, $17 \mathrm{~cm}$ in height by SGC; specimen of $10 \mathrm{~cm}$ in diameter, $15 \mathrm{~cm}$ in height made by coring and cutting;

Test parameters: four test temperatures $\left(5^{\circ} \mathrm{C}, 20^{\circ} \mathrm{C}, 40^{\circ} \mathrm{C}\right.$ and $\left.55^{\circ} \mathrm{C}\right)$; Nine loading frequency $(25 \mathrm{~Hz}$, $20 \mathrm{~Hz}, 10 \mathrm{~Hz}, 5 \mathrm{~Hz}, 2 \mathrm{~Hz}, 1 \mathrm{~Hz}, 0.5 \mathrm{~Hz}, 0.2 \mathrm{~Hz}$ and $0.1 \mathrm{~Hz}$ ). The load pattern could be half sinusoid. Each cyclic loading time is $0.1 \mathrm{~s}$ while with $0.9 \mathrm{~s}$ unloading time. While testing, the sequence of warming and lower frequency must be followed.

Data processing method: it fits dynamic modulus testing results into master curve with reference temperature of $20^{\circ} \mathrm{C}$ on the basis of time-temperature equivalence principle of asphalt mixture. The master curve of dynamic modulus is fitted with Sigamodal function, and the master curve of phase angle is fitted with Gauss curve and adopted the same shift factor as dynamic modulus master curve.

\section{Results and Discussion}

Results of tire-pavement noise spectrum

Tire-pavement noise of asphalt-rubber pavement and stone mustic asphalt pavement had been measured for five times on Chang'an avenue, testing time included September 2009, October 2009, December 2009 , January 2010 , March 2012 . At the time, the temperature was $30^{\circ} \mathrm{C}, 20^{\circ} \mathrm{C}, 0^{\circ} \mathrm{C}, 0^{\circ} \mathrm{C}$ and $0^{\circ} \mathrm{Cin}$ turn. The two sections of pavement were adjacent and had been built at the same time in August of 2009. The void of pavement was nearly the same, respectively $4.2 \%$ and $4.8 \%$, as well as Texture depth on surface were 1.2 and 1.1 . The testing speed was $50 \mathrm{~km} / \mathrm{h}$, and the result is shown by average A-weight sound level under third octave-band frequency.

Table 2: Testing results of tire-pavement noise(CPXT method )

\begin{tabular}{|c|c|c|c|c|c|c|c|c|c|c|}
\hline \multirow{2}{*}{$\begin{array}{l}\text { Iterp } \\
\text { Frequency } \\
(\mathrm{Hz})\end{array}$} & \multicolumn{2}{|l|}{$30^{\circ} \mathrm{C}(2009)$} & \multicolumn{2}{|l|}{$20^{\circ} \mathrm{C}(2009)$} & \multicolumn{2}{|l|}{$0^{\circ} \mathrm{C}(2009)$} & \multicolumn{2}{|l|}{$0^{\circ} \mathrm{C}(2010)$} & \multicolumn{2}{|l|}{$0^{\circ} \mathrm{C}(2011)$} \\
\hline & ARAC-13 & SMA-13 & ARAC-13 & SMA-13 & ARAC-13 & SMA-13 & ARAC-13 & SMA-13 & ARAC- 13 & SMA-13 \\
\hline 16 & 46.5 & 47.7 & 46.1 & 48.6 & 46.5 & 47.2 & 49.3 & 45.2 & 48.8 & 46.3 \\
\hline 31.5 & 52.8 & 52.2 & 53.5 & 52.8 & 53.0 & 53.6 & 55.8 & 50.3 & 54.3 & 50.7 \\
\hline 63 & 60.2 & 54.9 & 59.1 & 56.5 & 60.0 & 55.7 & 60.0 & 55.8 & 58.1 & 55.6 \\
\hline 125 & 64.1 & 58.3 & 62.7 & 62.1 & 60.7 & 62.1 & 63.0 & 60.4 & 63.0 & 59.3 \\
\hline 250 & 68.7 & 68.0 & 67.8 & 70.7 & 69.3 & 72.0 & 71.1 & 70.5 & 71.3 & 70.2 \\
\hline 500 & 76.3 & 78.0 & 76.1 & 79.9 & 78.9 & 81.3 & 79.6 & 78.9 & 80.9 & 80.3 \\
\hline 800 & 81.4 & 80.9 & 80.5 & 84.2 & 82.9 & 86.1 & 83.7 & 82.0 & 85.0 & 83.9 \\
\hline 1000 & 84.1 & 87.4 & 85.2 & 88.4 & 86.7 & 91.2 & 87.6 & 88.1 & 89.7 & 88.5 \\
\hline 2000 & 81.0 & 84.2 & 83.0 & 85.4 & 85.7 & 86.8 & 83.9 & 85.4 & 86.6 & 84.7 \\
\hline 4000 & 71.2 & 72.0 & 71.5 & 73.5 & 74.3 & 73.7 & 73.6 & 76.1 & 74.1 & 73.0 \\
\hline 5000 & 67.2 & 67.7 & 66.6 & 68.4 & 69.7 & 68.3 & 69.1 & 74.7 & 69.3 & 67.9 \\
\hline 6300 & 60.0 & 59.5 & 59.3 & 63.8 & 62.8 & 63.7 & 64.8 & 72.9 & 64.4 & 63.0 \\
\hline 8000 & 52.7 & 53.4 & 52.0 & 57.5 & 56.3 & 57.5 & 58.9 & 69.5 & 58.1 & 58.2 \\
\hline 10000 & 48.8 & 50.9 & 48.3 & 53.5 & 52.2 & 52.8 & 55.8 & 68.1 & 54.0 & 54.6 \\
\hline $\begin{array}{ll}\text { Average } & \text { sound } \\
\text { level }(\mathrm{dB}) & \\
\end{array}$ & 91.2 & 94.1 & 92.4 & 95.4 & 94.2 & 97.3 & 94.9 & 98.6 & 96.5 & 99.1 \\
\hline Difference(dB ) & \multicolumn{2}{|l|}{2.9} & \multicolumn{2}{|l|}{3.0} & \multicolumn{2}{|l|}{3.1} & \multicolumn{2}{|l|}{3.7} & \multicolumn{2}{|l|}{2.6} \\
\hline
\end{tabular}




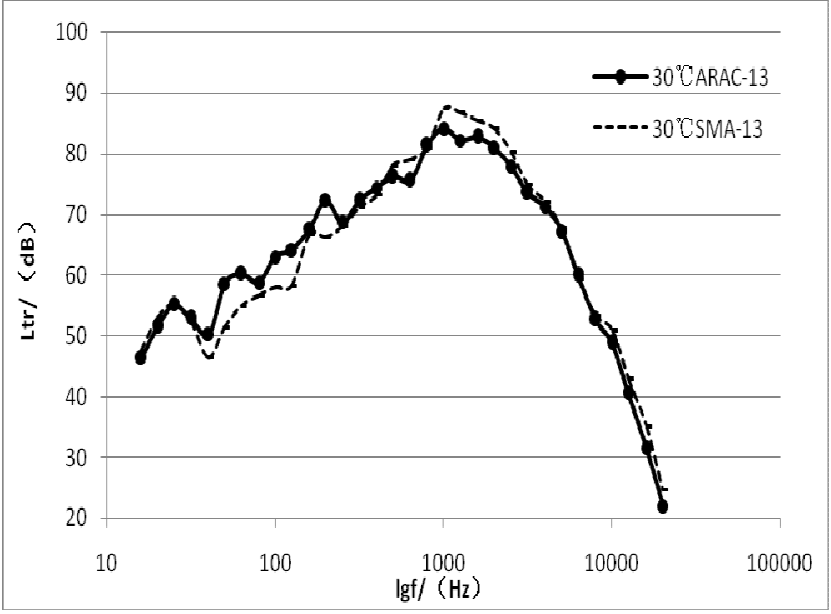

a:Temperature of pavement $30^{\circ} \mathrm{C}$

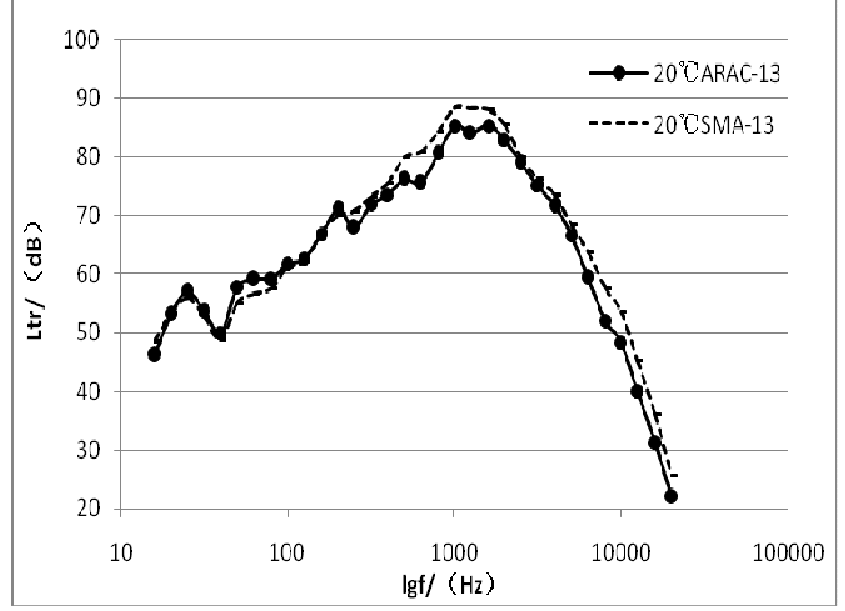

b:Temperature of pavement $20^{\circ} \mathrm{C}$

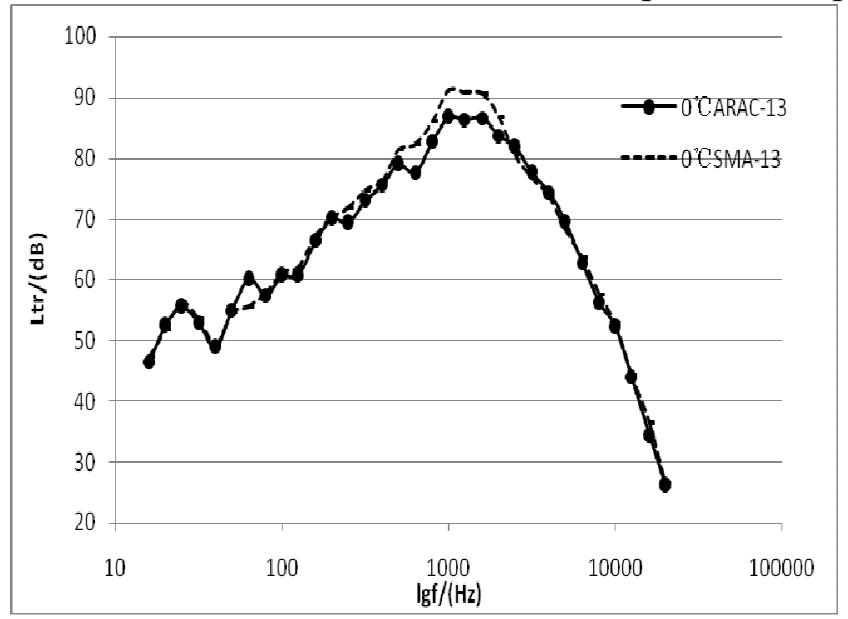

c:Temperature of pavement $0^{\circ} \mathrm{C}$

Figure 1: Noise spectrum of two types of pavement under different temperature in 2009

Figure 1 shows the comparison of two types of pavement noise spectrum under different temperatures, namely, $30^{\circ} \mathrm{C}, 20^{\circ} \mathrm{C}$ and $0^{\circ} \mathrm{C}$. These noise spectrum of asphalt-rubber pavement was compared with that of stone mustic asphalt pavement, the shape was nearly the same, but the sound level is lower while the frequency lay on the range of higher than $800 \mathrm{~Hz}$, and the low limit frequency decreased from $800 \mathrm{~Hz}$ to $63 \mathrm{~Hz}$ when the temperature decreased from $30^{\circ} \mathrm{C}$ to $0^{\circ} \mathrm{C}$. It shows that asphalt-rubber pavement could reduce tire-pavement noise in a wide range of temperature and frequency, it could reduce about $3 \mathrm{~dB}(\mathrm{~A})$ compared with stone mustic asphalt pavement.

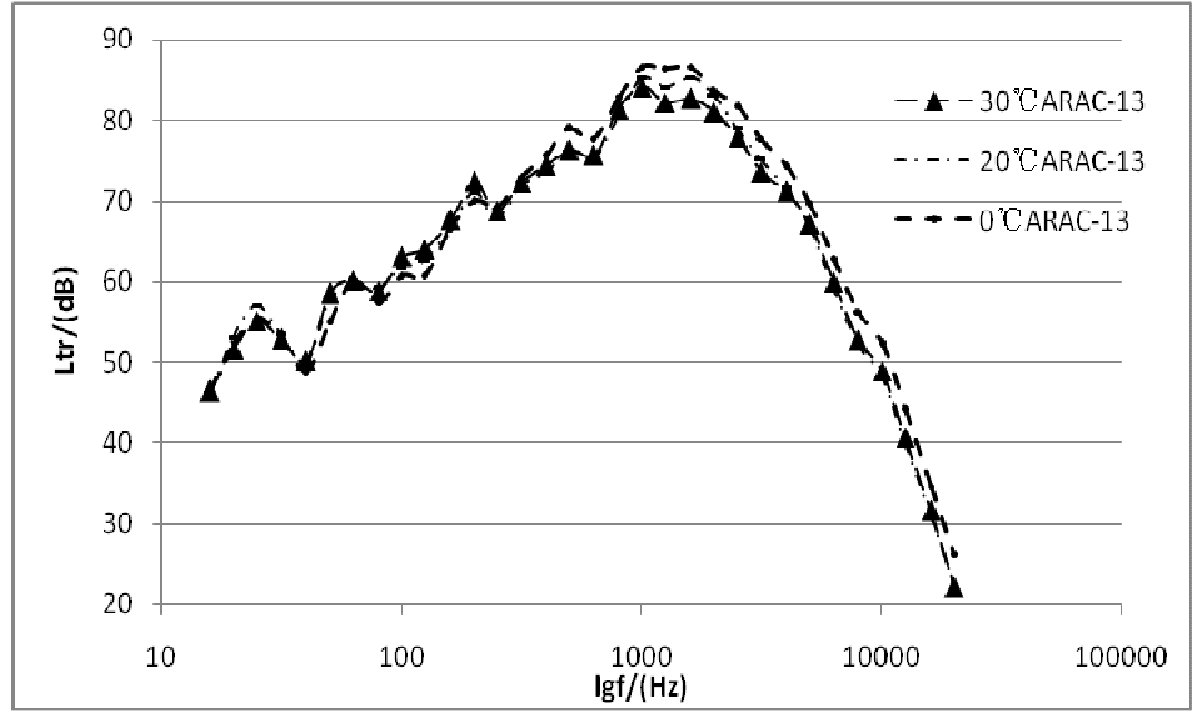

Figure 2: Noise spectrum of asphalt-rubber pavement under different temperature 


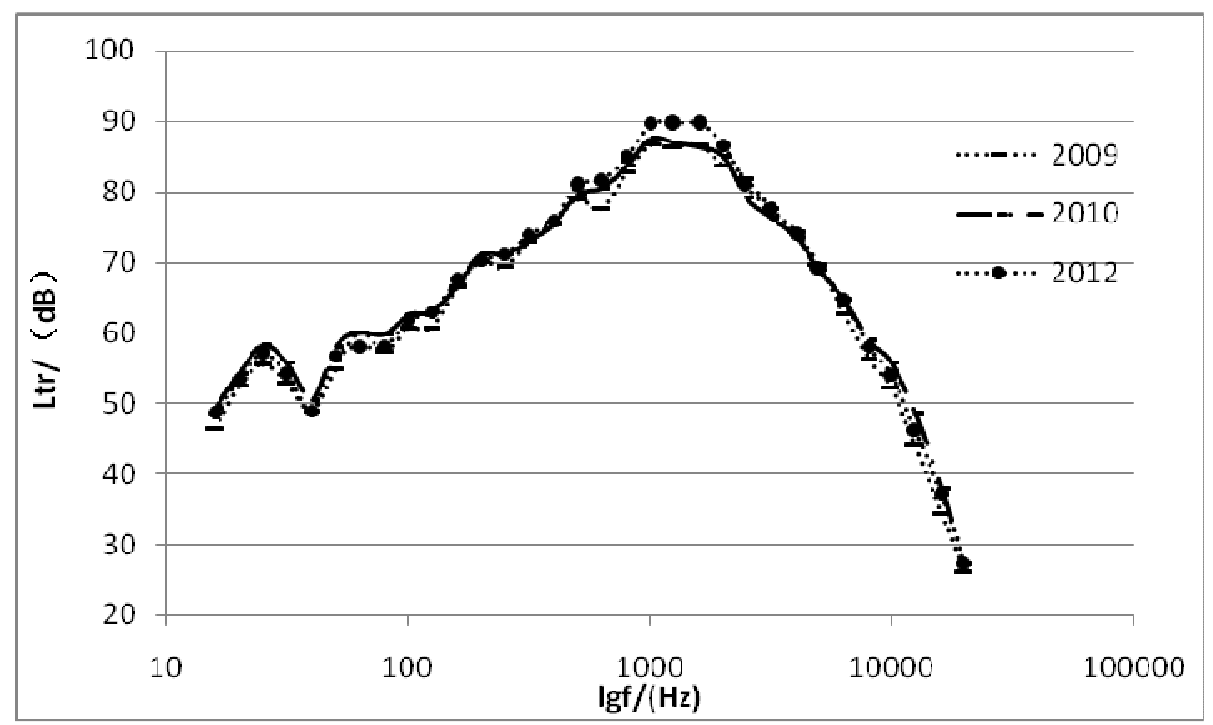

Figure 3: Noise spectrum of asphalt-rubber pavement in different age of pavement $\left(0^{\circ} \mathrm{C}\right)$

Figure 2 and Figure 3 shows regular pattern of noise spectrum of asphalt-rubber pavement changing with the temperature and age of pavement. The tire-pavement noise sound level could increase, especially sharply higher during the frequency $500 \mathrm{~Hz} \sim 2500 \mathrm{~Hz}$ in the noise spectrum when the temperature is decreased and age of pavement grows.
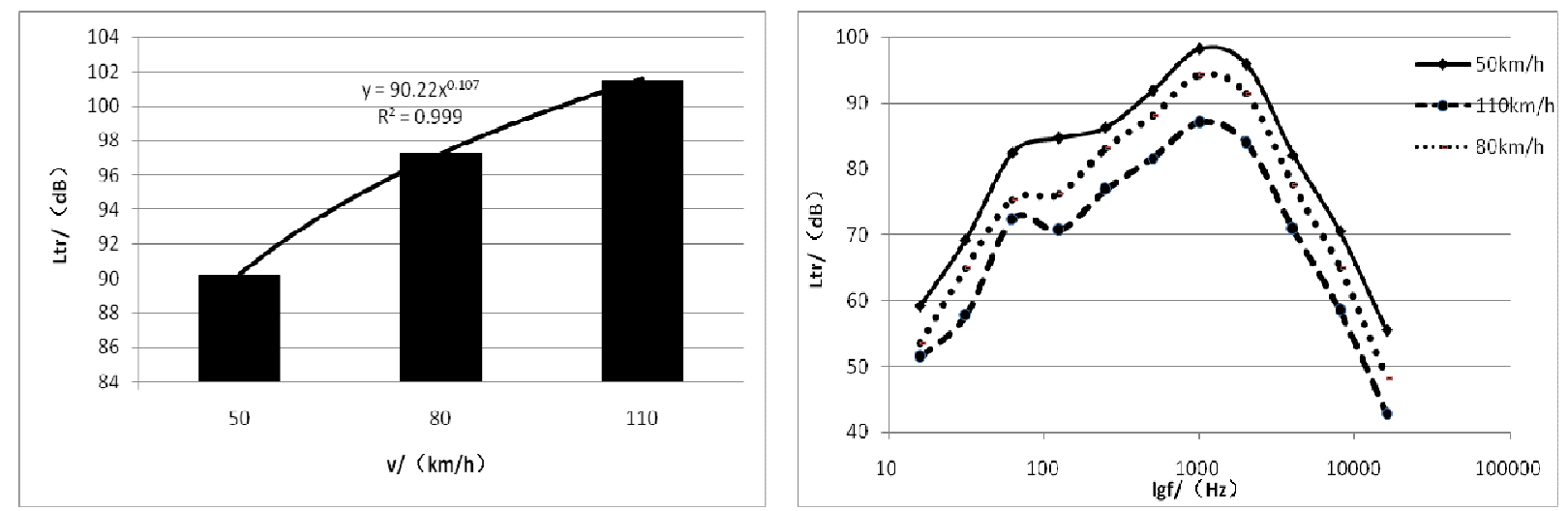

Figure 4: Average A-weight sound level of asphalt-rubber pavement at different testing speed

Figure 5: Noise spectrum of asphalt-rubber pavement at different testing speed

Figure 4 and Figure 5 show the effect of testing speed on tire-pavement noise of asphalt-rubber pavement. Another section of asphalt-rubber pavement in Beijing was chosen because of speed restriction in Chang'an avenue. The testing speeds were as follows: $50 \mathrm{~km} / \mathrm{h}, 80 \mathrm{~km} / \mathrm{h}$ and $110 \mathrm{~km} / \mathrm{h}$. Average A-weight sound level was increased in the form of approximate power law function with the increase of testing speed. The shape of noise spectrum shows no change, the sound level was increased during the entire range of testing frequency, and specially higher during the frequency $125 \mathrm{~Hz} \sim 2000 \mathrm{~Hz}$ in the noise spectrum.

The difference of viscoelasticity between asphalt-rubber concrete and stone mustic asphalt concrete

The materials of asphalt-rubber concrete(ARAC-13) and stone mustic asphalt concrete(SMA-13) were just the same as the pavement of Chang'an avenue paved in 2009. And their air voids of specimens are all 4\%. The results are shown as below: 

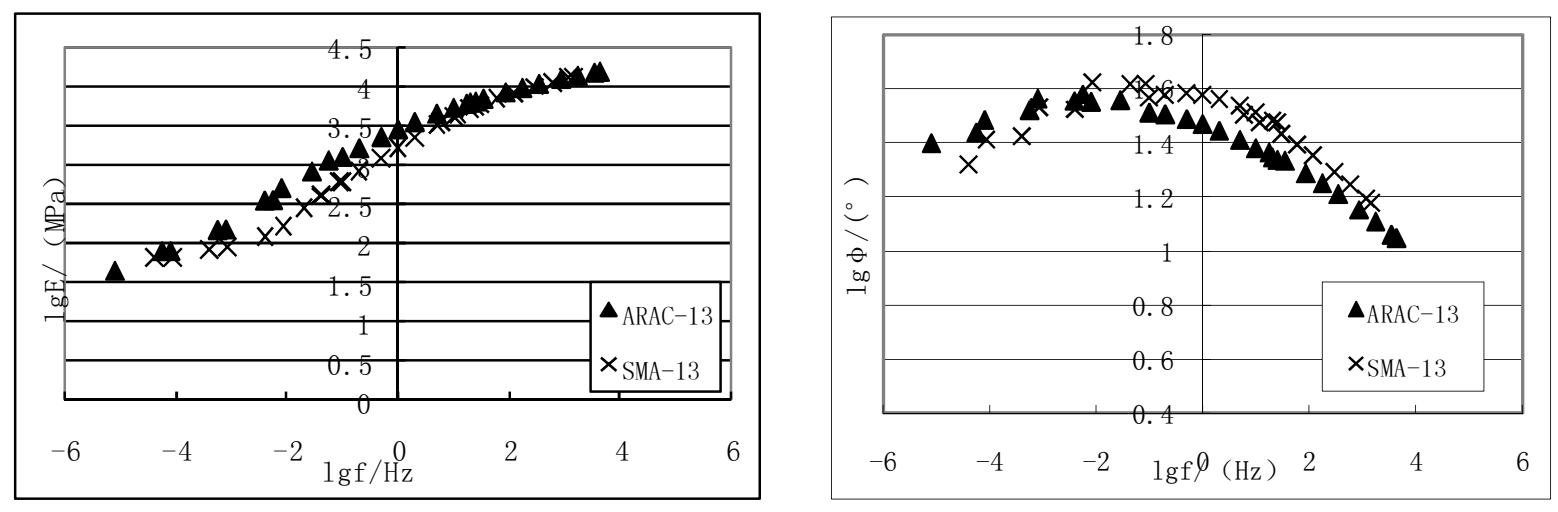

Figure 6: Dynamic modulus master curve of ARAC-13 and SMA-13 asphalt concrete

Figure 7: Phase angle master curve of ARAC-13 and SMA-13 asphalt mixture

As it can be seen from Figure 6 and Figure, ARAC-13 asphalt concrete's dynamic complex modulus was comparatively larger with more excellent elasticity in the most of frequency, and its phase angle is also comparatively smaller in the most of frequency compared with SMA-13 asphalt concrete. In other words, ARAC-13 asphalt concrete has more excellent elasticity than SMA-13 asphalt concrete in a wide range of frequency, which contributes to the reduction of tire-pavement noise greatly at wide vehicle speed as well as temperature change.

\section{Conclusions}

1. Asphalt-rubber pavement could reduce tire-pavement noise in a wide range of temperature and frequency and it could reduce about $3 \mathrm{~dB}(\mathrm{~A})$ in average A-weight sound level compared with stone mustic asphalt. Its sound level is lower while the frequency is based on the range higher than $800 \mathrm{~Hz}$, and this low limit frequency decreased from $800 \mathrm{~Hz}$ to $63 \mathrm{~Hz}$ when the temperature decreased from $30^{\circ} \mathrm{C}$ to $0^{\circ} \mathrm{C}$.

2.The tire-pavement noise sound level could get higher and higher during the frequency of $500 \mathrm{~Hz} \sim 2500 \mathrm{~Hz}$ in the noise spectrum, while the testing speed increases, or the temperature decreases, or the age of pavement grows.

3.ARAC-13 asphalt concrete has better elasticity than SMA-13 asphalt concrete in a wide range of frequency, which contributes to the reduction of tire-pavement noise greatly at wide vehicle speed as well as temperature change.

4. The peak value concentrates on the range of frequency $500 \mathrm{~Hz}$ to $2500 \mathrm{~Hz}$. So for noise spectrum of asphalt-rubber pavement, how to reduce noise sound level which lay on the range, and that is very important for the next step to research noise reduction asphalt-rubber pavement.

\section{Acknowledgments}

This material describes parts of research activities requested and sponsored by the Beijing Municipal Science \& Technology Commission. Its sponsorship of the research and the contributions of Research Institute of Highway Ministry of Transportation are gratefully acknowledged. The contents of this publication reflect the views of the authors and do not necessarily reflect the official views or policies of Beijing Municipal Government or Research Institute of Highway Ministry of Transportation. 


\section{References}

[1] WANG Xu-dong, LI Mei-jiang, LU Kai-ji. The Applied Technology of the Crumb Rubber in the Asphalt and Mixture [M]. Beijing: People's Communications Press, March 2008.

[2] Research Institute of Highway Ministry of Transport. Asphalt mixture Design Report of Maintenance Projects Chang'an Avenue in Beijing[R]. Beijing: Research Institute of Highway Ministry of Transport

[3] International Organization of Standardization. "ISO/CD 11819-2.Acoustics-Method for measuring the influence of road surfaces on traffic noise-Part 2: the close-proximity method" [S], ISO, Geneva, Switzerland, December 2000

[4] Paul R. Donavan, Dana M. Lodico. "Measuring Tire-Pavement Noise at the Source" [R]. Washington, D.C: Transportation Research Board, 2009

[5] Robert Otto Rasmussen. "Tire/pavement and Environmental Traffic Noise Research Study" [R]. Denver: Colorado Department of Transportation DTD Applied and Innovation Branch, January 2011

[6] MA Xiang, NI Fu-jian, CHEN Rong-sheng. Dynamic Modulus Test of Asphalt Mixture and Prediction Model [J]. China Journal of Highway and Transport.2008.5.21(3):P35

[7] Qing Lu, Erwin Kohler, John T. Harvey, Aybike Ongel. "Investigation of Noise and Durability Performance Trends for Asphaltic Pavement Surface Types: Three-Year Results" [R]. Davis: University of California Pavement Research Center UC Davis, UC Berkeley, January 2009

[8] Douglas I. Hanson, Robert S. James, Christopher NeSmith. "Tire/pavement Noise Study" [R]. Alabama: Auburn University, August 2004 [8] WANG Xu-dong, PENG Jing-wu, LI Mei-jiang, SHEN Guo-hui, ZHOU Xing-ye, ZHANG Lei. Trailer with Weight for Tre/road Noise Measurements, China: CN201327413 [P]:2010

[9] CHEN Ke-an, ZENG Xiang-yang, YANG You-liang. Acoustic Detecting [M].Beijing: China Machine Press, August 2010 